\title{
A comparative study on type I tympanoplasty with or without mastoidectomy in chronic otitis media-mucosal disease
}

\author{
Jaseetha S. $^{1}$, Srivastava T. ${ }^{2}$, Bhargava $A .^{3}$ \\ ${ }^{1}$ Dr. Jaseetha. S., Assistant Professor, ${ }^{2}$ Dr. Trisha Srivastava, Senior Resident, ${ }^{3}$ Dr. Aditya Bhargava, Professor; all \\ authors are affiliated with Department of ENT, PGIMSR \& ESIC Model Hospital, Basaidarapur, New Delhi, India.
}

Corresponding Author: Dr. Jaseetha S., Department of ENT, PGIMSR \& ESIC Model Hospital, Basaidarapur, New Delhi. Email id: drjesy@yahoo.co.in

\begin{abstract}
Introduction: This comparative study evaluates the outcomes of type 1 tympanoplasty with or without mastoidectomy in chronic otitis media, mucosal disease in a tertiary care institute. Materials and methods: The study included 84 patients with mucosal type of ear disease in quiescent stage .42 of these patients underwent type 1 tympanoplasty alone [Group A] and 42 underwent type 1 tympanoplasty with mastoidectomy [Group B]. Patients were followed up in the outpatient clinic at one week, third week, three months, and six months after the surgery. At third and sixth month the patients underwent otoscopic evaluation and hearing assessment. Results: $19 \%$ of the patients who underwent Type I tympanoplasty had residual perforation at 6 months when compared with $14 \%$ of the patients of cortical mastoidectomy with Type I tympanoplasty which was statistically insignificant in this study. In group B out of 7 patients who had diseased mastoid status per operatively 4 had residual perforation which was significant $[\mathrm{p}<0.05]$. Conclusion: In this study the comparison of results between groups A \& B is statistically insignificant. Disease status of mastoid proved to be a significant factor for success of surgery. Belfast rule of thumb proved to be a better method to assess the postoperative hearing improvement subjectively.
\end{abstract}

Keywords: Chronic otitis media, Tympanoplasty, Mastoidectomy

\section{Introduction}

Chronic otitis media (COM) is an inflammatory process in the middle-ear space that results in long-term, or more often, permanent changes in the tympanic membrane including atelectasis, dimer (formerly "monomer") formation, perforation, tympanosclerosis, retraction pocket development, or cholesteatoma [1].

Higher incidence is observed in developing country because of overcrowding, inadequate healthcare, poor hygiene, recurrent upper respiratory tract infections, poor nutrition. Prevalence surveys, show that the global burden of illness from CSOM involves 65-330 million individuals with draining ears, $60 \%$ of whom (39-200 million) suffer from significant hearing impairment [2]. Granulation tissue within the middle ear cleft and mastoid is also a nearly omnipresent finding in CSOM, observed in 93 to $98 \%$ of temporal bone specimens. The epitympanum and round window niche were the most frequent areas of involvement in temporal bone studies,

Manuscript received: $20^{\text {th }}$ August 2018

Reviewed: $30^{\text {th }}$ August 2018

Author Corrected: $4^{\text {th }}$ September 2018

Accepted for Publication: $7^{\text {th }}$ September 2018 but as is often the case, granulation tissue involvement of the entire middle ear cleft, to some degree, was conspicuous in all specimens. Granulation tissue blocking the aditus can prevent aeration of the mastoid and subsequent resolution of infection [3].

Chronic otitis media is one of the major cause of recoverable conductive deafness that an otologist diagnose and treat. Cortical mastoidectomy along with repair of tympanic membrane perforation and ossicular chain has for long been considered a surgical procedure of choice for chronic otitis media - active mucosal disease. The three priorities in surgery for CSOM are eradication of disease, prevention of disease recurrence and preservation or restoration of hearing. Tympanoplasty is "a procedure to eradicate disease in the middle ear and to reconstruct the hearing mechanism, with or without tympanic membrane grafting." This procedure can be combined with either an intact canal wall (ICW) or a canal-wall-down (CWD) mastoidectomy to eradicate disease from the mastoid area [4]. 
The otologist performing an ear surgery aims at making the patient free of ear discharge \& to improve the hearing. As a precautionary measure many surgeons perform mastoidectomy and tympanoplasty for mucosal disease for fear of infection lurking in and around the middle ear cleft leading to recurrence and graft failure irrespective of the stage of disease. If a mastoidectomy could be avoided where it was unnecessary, time and effort could be saved, thereby reducing complications of mastoidectomy which outweighs the beneficial effects of closure of tympanic membrane perforation [5]. This study is to compare the results of Type I tympanoplasty with or without cortical mastoidectomy in chronic otitis media, mucosal disease.

\section{Aims and Objectives}

- To compare the surgical outcomes of cortical mastoidectomy with Type I tympanoplasty and Type I tympanoplasty alone in cases of chronic otitis media, mucosal disease.

- To find out the prognostic factors influencing the surgical outcome.

- To find out the post surgical hearing outcome.

- To analyze the role of cortical mastoidectomy in chronic otitis media, mucosal disease in quiescent stage.

\section{Materials and Methodss}

This retrospective study was conducted in a group of 84 patients who were selected using non probabilitypurposive sampling method in upgraded institute of otorhinolaryngology, Madras Medical Collage, Chennai.

Inclusion criteria: Chronic Otitis media with mucosal disease with the following criteria were included:-

- More than one month but less than three months elapsed since last ear discharge

- Central perforation

\section{Exclusion criteria}

- Patients with presence of mucopurulent ear discharge or dry central perforation > 3 months

- Granulation tissue, polyp, cholesteatoma in ear

- Multiple TM perforation

- Clinically significant predisposing focus of infection in nose and throat

- Patients with previous ear surgeries

- Patients with sensory neural hearing loss.

- Traumatic perforation

- Patients with systemic illness.
Methodology- The patients with above criteria were included. The preoperative details were collected from the related documents in the institute. Patients who underwent Type I tympanoplasty were considered as group A and who underwent Type I tympanoplasty with cortical mastoidectomy were under group B.

All patients were admitted and the routine preoperative investigations were done. All patients underwent pure tone audiometry, Eustachian tube patency tests and Xray mastoids Law's view. A detailed written informed consent was taken. Surgical procedures were done either in local anesthesia or in general anesthesia. Both post aural and per meatal approach was performed. Tympanomeatal flap elevation and the underlay technique were performed in all cases.

In group A Type I tympanoplasty was done, patency of aditus not checked the mastoid antrum was not opened. In group $\mathrm{B}$ cortical mastoidectomy with Type I tympanoplasty was done, the patency of aditus checked and established. Patients were put on I.V antibiotics and discharged on third post-operative day.

Patients were followed up in the outpatient clinic at one week, third week, three months, and six months after the surgery. At third and sixth month the patients underwent otoscopic evaluation and PTA.

Outcomes of the study that was evaluated are as follows:

- Eradication of the disease

- Closure of the perforation

- Improvement in hearing status by PTA and application of Belfast rule of thumb for assessing the hearing improvement

Belfast rule of thumb- Based on the analysis of the relation between patient's perceived subjective benefit and postoperative audiometric changes Smyth and Patterson developed Belfast rule of thumb. Patients are likely to derive significant benefit post operatively if the air conduction threshold in speech frequencies $(0.5,1,2$ $\mathrm{KHz}$ ) was less than or equal to $30 \mathrm{~dB}$ or if the inter aural difference is reduced to less than or equal to $15 \mathrm{~dB}$ [6].

Classification based on air bone gap are classified as,

Excellent $-<10 \mathrm{~dB}$

Good -11 TO $20 \mathrm{~dB}$

Fair - 21 TO $30 \mathrm{~dB}$

The statistical analysis of the data was done using paired t- test. 


\section{Results}

There were 84 patients who registered in this study. They had chronic otitis media, mucosal disease. Among 84 patients 49 were females $(58.3 \%)$ and $35(41.7 \%)$ were males. Median age was 30 . Out of 84 patients; the graft take up rate in this study was $83.3 \%$ and $16.7 \%$ had residual perforation. Incidence of residual perforation were more in the age group above $35,31.25 \%$ were in age group $35-44$ and $23.1 \%$ were in the age group $45-50.8 .7 \%$ patients who had RP were in the age group 15-24 and 12.5\% were in the age group 25-34. The mean pre op PTA for the study population was $40 \mathrm{~dB}$ with a standard deviation of 4.04. The post op PTA at 6 months was $20 \mathrm{~dB}+/-4.06 \mathrm{~dB}$. The hearing improvement was found to be significant with a $\mathrm{p}$ value $<0.04$.

Table-1: Correlation of perforation size and pre op ABG

\begin{tabular}{|c|c|c|}
\hline \multirow{2}{*}{ Perforation Size } & \multicolumn{2}{|c|}{ Pre op ABG (Air-Bone gap) } \\
\cline { 2 - 3 } & Fair (20-30 dB) & Good (10-20 dB) \\
\hline Medium $(\mathrm{n}=63)$ & $\mathrm{n}=51(81 \%)$ & $\mathrm{n}=12(19 \%)$ \\
\hline Subtotal $(\mathrm{n}=21)$ & $\mathrm{n}=17(81 \%)$ & $\mathrm{n}=4(19 \%)$ \\
\hline
\end{tabular}

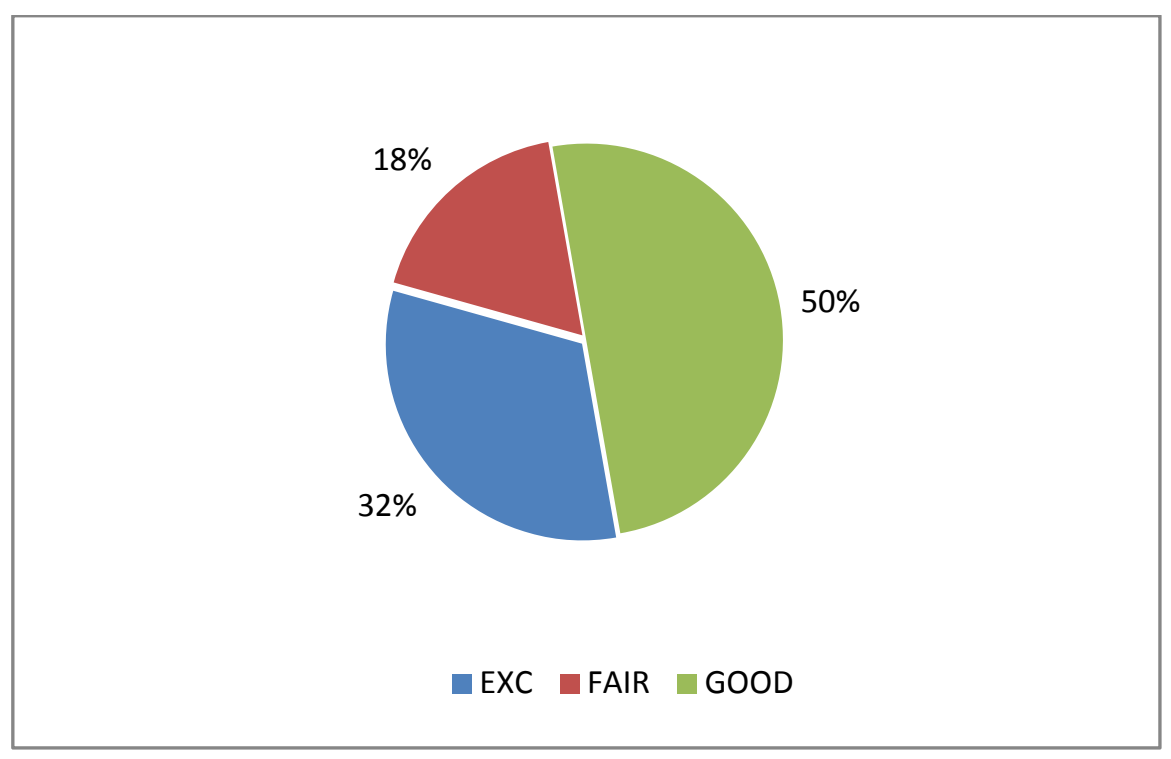

Graph-1: Post op ABG at 6 months

The overall hearing benefit was $82.1 \%$, excellent with $<10 \mathrm{~dB}$ ABG closure was $32.1 \%$; good with $<20 \mathrm{~dB}$ was $50 \%$ and $17.9 \%$ had ABG of 20-30 dB.[graph 1]

Table 2- Correlation of pneumatization of mastoid with rate of graft uptake

\begin{tabular}{|c|c|c|}
\hline Mastoid X-ray & Intact Graft & Residual Perforation \\
\hline Pnuematised & $\mathrm{n}=51 ; 85 \%$ & $\mathrm{n}=9 ; 15 \%$ \\
\hline Sclerosed & $\mathrm{n}=19 ; 79.2 \%$ & $\mathrm{n}=5 ; 20.8 \%$ \\
\hline
\end{tabular}

60 patients had pneumatised mastoid and 24 had sclerosed mastoid, of which 51(85\%) among 60 had intact graft at 6 months whereas $19(79.2 \%)$ among 24 had intact graft at the same time period. The difference was statistically not significant [Table 2].

Among 63 patients who had medium size perforation, 55 had intact graft (87.3\%). Among 21 patients who had subtotal perforation, $28.6 \%$ had residual perforation, which indicates size of perforation does have a role in graft take up rate. 
Table 3-Application of Belfast rule of thumb to post op ABG.

\begin{tabular}{|c|c|c|c|}
\hline \multirow{2}{*}{ POST-OP ABG } & \multicolumn{2}{|c|}{ Application of Belfast Rule of Thumb } \\
\cline { 2 - 4 } & Better & Same & Poor \\
\hline Excellent $(<10 \mathrm{~dB})$ & $\mathrm{n}=27(100 \%)$ & $\mathrm{n}=0$ & $\mathrm{n}=0$ \\
\hline Good $(11-20 \mathrm{~dB})$ & $\mathrm{n}=37(88.1 \%)$ & $\mathrm{n}=0$ & $\mathrm{n}=13(11.9 \%)$ \\
\hline Fair $(21-30 \mathrm{~dB})$ & $\mathrm{n}=1(6.7 \%)$ & $\mathrm{n}=1(6.7 \%)$ & \\
\hline
\end{tabular}

When Belfast rule of thumb was applied to assess the post-operative hearing improvement subjectively, 37 patients had a better hearing and 27 had excellent. This was compared with the post -op ABG, had a highly significant p-value $(<0.00001)$, which indicates that this rule interprets post-op hearing benefit in a better way subjectively. (Table 3 )

In group A, 27 patients were females and 15 were males, graft take up was $81 \%$.

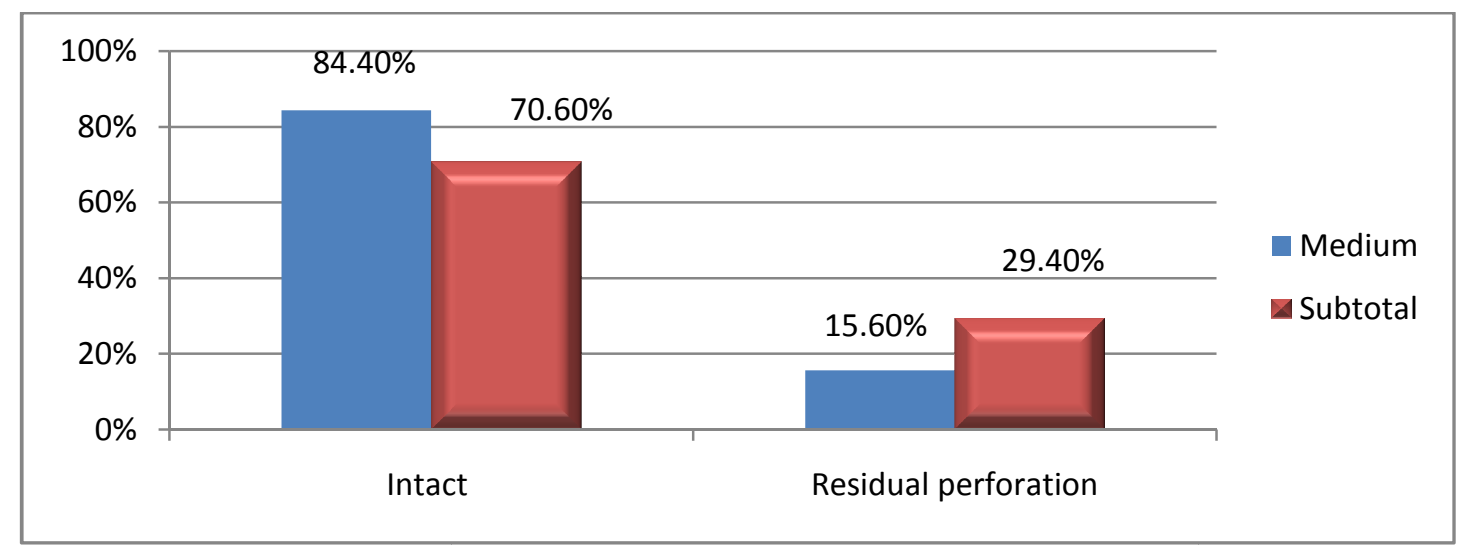

Graph-2: Size of perforation Vs TM status at 6 months in Group A

Out of 32 patients who had medium size perforation, 27 had intact graft (84.4\%) and 5 had RP (15.6\%), among 10 patients who had subtotal perforation 7 had intact graft (70.6\%) and 3 had RP (29.4\%) which is statistically insignificant (Graph-2).

Among 27 patients who had ear discharge for less than 5 years, 22 patients had intact graft (81.5\%) and in 15 patients who are having more than 5 years ear discharge $80 \%$ had intact graft of 6 months, which was statistically insignificant On comparison of pre op $\mathrm{ABG}$ and post op $\mathrm{ABG}, 41$ patients who had fair ABG, 33 patients improved and had better post op ABG.

Type of approach for surgery does not have significant p-value with graft take up in this study. The other parameters like age and sex does not have any influence on the outcome in this study.

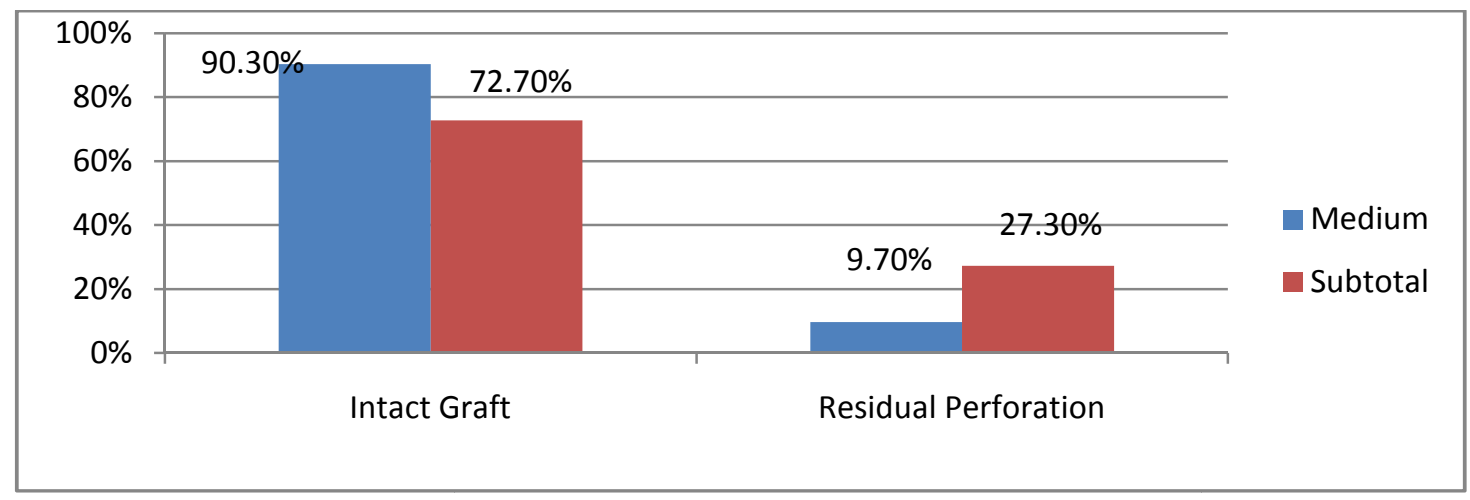

Graph- 3: Size of perforation Vs TM status at 6 months in Group B 
In group B, 22 patients were females and 20 were males. 31 had medium size perforation and 11 had subtotal perforation. Overall graft takes up was $85 \%$.

Among 31 patients who had medium size perforation 28 had intact graft of 6 months which comes around $90.3 \%$ and out of 11 patients with subtotal perforation, 8 had intact graft (72.7\%) and 3 had RP (27.3\%) (Graph 3).

Out of 42 patients, 7 had disease mastoid and 35 had healthy or hypertrophied mucosa. 4 patients, who had disease mastoid, had residual perforation at 6 months and 2 patients who had healthy mucosa had residual perforation at 6 months. Disease status of mastoid antrum proved to have a highly significant role in graft take up in this study $[\mathrm{p}$ value $=0$ $.000386]$.

\section{Discussion}

In this study 84 cases underwent surgery for chronic otitis media, mucosal disease. The graft uptake rate in Group A was $81 \%$ and in Group B was $85 \%$ respectively. Ashok et al observed similar results with $80 \%$ graft uptake in patients with tympanoplasty alone when compared to $100 \%$ graft uptake in cases with tympanomastoidectomy [7].

Mishiro et al compared 104 ears treated by tympanoplasty alone with previous group of 147 ears treated by tympanoplasty with mastoidectomy [8]. There was no significant difference in the tympanic membrane closure rate between the 2 groups.

Graft failure rate- In this study 8 patients out of 63 who had medium size perforation, had residual perforation at 6 months (12.7\%) when compared with $28.6 \%$ patients with subtotal perforation. As the perforation size increases, chance of residual perforation is more.

The probable cause of residual perforation is the slippage of graft from its position and the cause for rejection is postoperative infection of the operated site. 19\% of the patients who underwent Type I tympanoplasty had residual perforation at 6 months when compared with 14\% of the patients of Type I tympanoplasty with cortical mastoidectomy which was statistically insignificant.

The disease status of the mastoid antrum has a significant role in graft take up. Therefore, assessment of the status of mastoid is necessary before planning a tympanoplasty.

Post-operative air bone gap- In this study $80.9 \%$ of the patients in group A had post op ABG less than $20 \mathrm{~dB}$ when compared with $83.4 \%$ of the patients in group B. One patient had sensory neural hearing loss after the surgery. In a study conducted by Krishnan et al $75 \%$ of patients who underwent tympanomastoidectomy in quiescent stage had hearing gain with $\mathrm{ABG}<20 \mathrm{~dB}$ when compared to $50 \%$ in cases who underwent tympanoplasty alone [9].

Mishiro et al found $90.4 \%$ of patients who underwent tympanoplasty had post op ABG < $20 \mathrm{~dB}$ when compared to $81.6 \%$ of patients who underwent tympanomastoidectomy [8].

Post-operative hearing benefit- On applying Belfast rule of thumb 27 patients who had excellent post-operative air bone closure $(<10 \mathrm{~dB})$ had better hearing subjectively (100\%). Of the 42 patients who had good post-operative air bone closure $(<10-20 \mathrm{~dB}), 37$ had better hearing and 5 had the same status subjectively.

This implies Belfast rule of thumb is better in subjective value of hearing benefit.

Role cortical mastoidectomy in chronic otitis media, mucosal disease- While mastoid reservoir of infection theory holds well in active CSOM the same may not be true in the quiescent or dry phase when active ear discharge is absent. In this study the comparison of results between groups A \& B is statistically insignificant.

McGrew et al in their paper on impact of mastoidectomy on simple TM perforation repair concluded that mastoidectomy improves the clinical course of disease and reduces the number of patients requiring future surgery disease progression [10]. 
Table-4: Studies supporting tympanomastoidectomy is cited.

\begin{tabular}{|c|c|c|c|c|c|}
\hline Study & $\begin{array}{l}\text { Sampl } \\
\text { e Size }\end{array}$ & Study Design & $\begin{array}{c}\text { Success Rate (graft } \\
\text { take up) }\end{array}$ & Post op Hearing Status & Year \\
\hline $\begin{array}{c}\text { Holmquist \& } \\
\text { Bergstorm [11] }\end{array}$ & 31 & Retrospective & MTP $83 \%$ TP $50 \%$ & -- & 1978 \\
\hline $\begin{array}{c}\text { Jackler \& } \\
\text { Schindler [12] }\end{array}$ & 48 & Retrospective & MTP $84.6 \%$ & Mean ABG $13.1 \mathrm{~dB}$ & 1984 \\
\hline Krishnan et al [9] & 120 & Prospective & $\begin{array}{c}\text { Quiescent: MTP } 80 \% \\
\text { TP 60\% } \\
\text { Dry: } \\
\text { MTP 100\% TP 78\% }\end{array}$ & $\begin{array}{c}\text { ABG }<20 \text { dB Q: MTP 75\% } \\
\text { TP 50\% } \\
\text { Dry: } \\
\text { MTP 80\% TP 55\% }\end{array}$ & 2002 \\
\hline $\begin{array}{c}\text { Nayak DR et al } \\
{[13]}\end{array}$ & 40 & Prospective & $\begin{array}{c}\text { MTP } 100 \% \\
\text { TP } 60 \%\end{array}$ & $\begin{array}{c}\text { Gain: } \\
\text { MTP } 20 \mathrm{~dB} \text { TP } 16 \mathrm{~dB}\end{array}$ & 2003 \\
\hline
\end{tabular}

In this study in Group B $94.3 \%$ of the patients who had disease-free mastoid antrum (33) had intact graft at 6 months, in these cases Type I tympanoplasty alone could be a preferable option.

Table-5: Studies not supporting tympanomastoidectomy in inactive mucosal disease is cited.

\begin{tabular}{|c|c|c|c|c|c|}
\hline Study & $\begin{array}{c}\text { Sample } \\
\text { Size }\end{array}$ & Study Design & $\begin{array}{c}\text { Success } \\
\text { Rate (graft } \\
\text { take up) }\end{array}$ & Post op Hearing Status & Year \\
\hline $\begin{array}{c}\text { Balyan et al } \\
{[14]}\end{array}$ & 81 & Retrospective & $\begin{array}{c}\text { MTP } 85.7 \% \\
\text { TP 90.5\% }\end{array}$ & $\begin{array}{c}\text { Mean ABG } \\
\text { MTP 20.1 dB } \\
\text { TP } 17.2 \mathrm{~dB}\end{array}$ & 1997 \\
\hline $\begin{array}{c}\text { Mishiro } \\
\text { et al [8] }\end{array}$ & 251 & Retrospective & $\begin{array}{c}\text { MTP 90.5\% } \\
\text { TP 93.3\% }\end{array}$ & $\begin{array}{c}\text { ABG <20 dB } \\
\text { MTP } 81.6 \% \text { TP 90.4\% }\end{array}$ & 2001 \\
\hline $\begin{array}{c}\text { Mc Grew } \\
\text { et al [10] }\end{array}$ & 484 & Retrospective & $\begin{array}{c}\text { MTP 91.6 } \% \\
\text { TP 90.6\% }\end{array}$ & $\begin{array}{c}\text { MTP } 14.4^{ \pm} 11.1 \mathrm{~dB} \\
\text { TP } 16.4^{ \pm} 12.4 \mathrm{~dB}\end{array}$ & 2004 \\
\hline
\end{tabular}

\section{Conclusion}

Henceforth we conclude that results of Type I tympanoplasty in terms of graft take up and hearing improvement did not vary much with cortical mastoidectomy with type I tympanoplasty in quiescent stage of COM mucosal disease.

However, the size of perforation and the status of mastoid antrum has a role in the results of the surgery. The Belfast rule of thumb proved to be a better subjective tool to assess hearing in post operative cases, however a larger sample size and further studies are required to conclusively prove it as an effective tool.

Declaration of Conflicting Interests- The author(s) declared no potential conflicts of interest with respect to the research, authorship, and/or publication of this article.

Funding- The author(s) received no financial support for the research, authorship, and/or publication of this article.
Funding: Nil, Conflict of interest: Nil

Permission from IRB: Yes

\section{References}

1. Quinton Gopen, MD Pathology and Clinical Course of the Inflammatory Diseases of the Middle Ear, Shambaugh ear surgery $6^{\text {th }}$ edition chapter 25: 425 .

2. Chronic Suppurative Otitis Media- Burden of Illness and Management Options, Child and Adolescent Health and Development Prevention of Blindness and Deafness, World Health Organization, Geneva, Switzerland 2004: 10-14

3. David S. Haynes, MD Justin Wittkopf, MD- Canal wall up mastoidectomy, Shambaugh ear surgery $6^{\text {th }}$ edition chapter 30: 502 .

4. Aristides Athanasiadis- Sismanis Tympanoplasty: tympanic membrane repair, Shambaugh ear surgery $6^{\text {th }}$ edition chapter 28: 465. 
5. Chavan S, Deshmukh S,Pawar V, Khobragade S, Sarvade K, [2011]. Tympanoplaty with and without cortical mastoidectomy for tubotympanic type of chronic suppurative otitis media. Otolaryngol Head Neck Surg 8 [1]: 8-10.

6. A Ravikumar, A Chawdery, K Senthil. Hearing benefit in middle ear reconstructive surgery: A comparative study of current methods. Indian J Otolaryngol Head Neck Surg2005; Jul;57[3]: 210-214.

7. Saha AK, Munsi DM, Ghosh SN. Evaluation of improvement of hearing in type I tympanoplasty \& its influencing factors. Indian J Otolaryngol Head Neck Surg. 2006 Jul;58(3):253-7. doi: 10.1007/BF 03050833.

8. Mishiro Y, Sakagami M, Takahashi Y, et al. Tympanoplasty with and without mastoidectomy for non-cholesteatomatous chronic otitis media. Eur Arch Otorhinolaryngol. 2001 Jan ;258 (1):13-5.

9. Krishnan A, Reddy EK, Chandrakiran C, et al. Tympanoplasty with and without cortical mastoidectom y - a comparative study. Indian J Otolaryngol Head
Neck Surg. 2002 Jul;54(3):195-8. doi: $10 . \quad 1007 /$ BF02993102.

10. McGrew BM, Jackson CG, Glasscock ME 3rd. Impact of mastoidectomy on simple tympanic membrane perforation repair. Laryngoscope. 2004 Mar;114(3):506-11.

11. Holmquist J, Bergström B. The mastoid air cell system in ear surgery. Arch Otolaryngol. 1978 Mar; 104 (3):127-9.

12. Jackler RK, Schindler RA. Role of the mastoid in tympanic membrane reconstruction. Laryngoscope. 1984 Apr;94(4):495-500.

13. Nayak D R, Balakrishnan R, Hazarika P, Mathew $P$ $\mathrm{T}$. role of cortical mastoidectomy in the results of myringoplastyfor dry ear 104;127-129.

14. Balyan FR, Celikkanat S, Aslan A, et al. Mastoidectomy in noncholesteatomatous chronic suppurative otitis media: is it necessary? Oto-laryngol Head Neck Surg. 1997 Dec;117(6):592-5.

\section{How to cite this article?}

Jaseetha S, Srivastava T, Bhargava A. A comparative study on type I tympanoplasty with or without mastoidectomy in chronic otitis media-mucosal disease. Trop J Ophthalmol Otolaryngol.2018;3 (3):51-57.doi: 10.17511/jooo.2018.i03.08 